\title{
GENERALISED TRAPEZOID TYPE INEQUALITIES FOR VECTOR-VALUED FUNCTIONS AND APPLICATIONS
}

\author{
C. Buşe, S. S. Dragomir, J. Roumeliotis and A. Sofo
}

Abstract. A generalisation of the trapezoid formula for vector-valued functions and applications for operatorial inequalities and vector-valued integral equations are given.

Mathematics subject classification (2000): 26D15, 26D99, 46B99.

Key words and phrases: Trapezoid Inequality, Bochner Integral.

\section{REFERENCES}

[1] P. CERONE AND S. S. DRAGOMIR, Trapezoidal-type rules from an inequalities point of wiew, in AnalyticComputational Methods in Applied Mathematics, (Ed. G. A. Anastassiou), Chapman \& Hall/CRC, 2000.

[2] J. Diestel and J. J. Uhl, JR., Vector Measures, Amer. Math. Society, Mathematical Surveys, 15, Providence, Rhode Island, (1977).

[3] H. O. FATTORINI, Second Order Linear Differential Equations in Banach Spaces, Elsevier, Amsterdam, 1985.

[4] R. NAGEL(ED.), One-Parameter Semigroups of Positive Operators, Springer Lecture Notes in Mathematics, 1184 (1986).

[5] A. PAZY, Semigroups of Linear Operators and Applications to Partial Differential Equations, Springer Verlag, 1983.

[6] J. PRÜSS, Evolutionary Integral Equations and Applications, Monographs in Mathematics, Vol. 87, Birkhaüser Verlag, New York, 1993.

[7] E. ScHÜLER, On the spectrum of cosine functions, Journal of Math. Analysis and Appl., 229 (1999), 376-398. 